九州大学学術情報リポジトリ

Kyushu University Institutional Repository

\title{
Drying Properties of Sugi Round Timber with Microwabe Heating
}

Piao, Jinji

Graduate School of Bioresource and Bioenvironmental Sciences, Kyushu University

Fuj imoto, Noboru

Faculty of Agriculture, Kyushu University

Ohashi, Kanehiro

Asia Se isakusyo

Tanikawa, Mitsuru

Xyence Corporation

他

https://doi.org/10.5109/9252

出版情報: 九州大学大学院農学研究院紀要. 51 (2)，pp. 345-349，2006-10-27. Faculty of Agriculture, Kyushu University

バージョン :

権利関係 : 


\title{
Drying Properties of Sugi Round Timber with Microwave Heating \\ Jinji PIAO ${ }^{1}$, Noboru FUJIMOTO*, Kanehiro OOHASHI ${ }^{2}$, Mitsuru TANIKAWA ${ }^{3}$, Masashi KITADA ${ }^{3}$, Hozumi SONOBE ${ }^{3}$ and Yo UEDA ${ }^{3}$
}

\author{
Laboratory of Wood Material Technology, Division of Biomaterial Science, Department of \\ Forest and Forest Products Sciences, Faculty of Agriculture, \\ Kyushu University, Fukuoka 812-8581, Japan \\ (Received June 30, 2006 and accepted July 24, 2006)
}

\begin{abstract}
Sugi round timbers injected with preservative are useful for outdoor playing and construction materials. To dry the Sugi round timbers for preservative injection, three drying methods including microwave drying, kiln drying and air drying were compared in this study. Using microwave drying, the timbers were dried within one day, but the other two drying methods required a much longer time. During most of the microwave drying process, the wood temperature appeared to be higher in the inner layer than in the outer layer. As a result, the inner layer moisture contents were significantly reduced by microwave drying, while kiln drying produced almost no decline in the inner layer moisture contents. In addition, although significant surface checks often occurred in timbers dried by kiln drying and air drying, microwave drying caused few surface checks. In contrast, internal checks were only observed in timbers treated by microwave drying. These results suggested that the microwave drying technique can improve the effectiveness of preservative injection in Sugi round timbers.
\end{abstract}

\section{INTRODUCTION}

Sugi (Cryptomeria japonica D. Don) boxed-heart round timber is often treated by preservative injection to prepare it for use in outdoor play equipment and engineering applications.

However, drying Sugi boxed-heart timber to a moisture content suitable for the injection of wood preservatives takes a very long time.

Moreover, Fujimoto et al. (1994) reported that surface checks occurred in the drying stage of Sugi boxed -heart timbers due to anisotropic shrinkage. Their results showed that when the microwave heating method is used, the inner layer of the timbers could be dried in a short time without surface checks (Fujimoto et al. 2005).

Therefore, in this study, the above microwave heating technique was adopted to quickly dry the inner parts of Sugi timber, which is difficult for wood preservatives to permeate. To clarify the drying properties of Sugi round timbers for microwave heating, the temperature distribution, moisture content distributions and qualities of the dried timber were measured during kiln drying and air drying as well as microwave drying.

\section{MATERIALS AND METHODS}

\section{Materials}

The drying test was carried out on Sugi boxed-heart round timbers (diameter of $12 \mathrm{~cm}$, length of $4 \mathrm{~m}$ ) with

\footnotetext{
${ }^{1}$ Laboratory of Wood Technology, Department of Forest and Forest Products Sciences, Graduate School of Bioresource and Bioenvironmental Sciences, Kyushu University

${ }^{2}$ Asia Seisakusyo

${ }^{3}$ Xyence Corporation

* Corresponding author (E-mail: fujipon@agr.kyushu-u.ac.jp)
}

and without a kerf. In order to assay the initial moisture content (MC) of the timbers, $2 \mathrm{~cm}$ thickness discs were sampled at points $30 \mathrm{~cm}$ from both ends (Fig. 1). The discs were divided so the average moisture content could be measured, and the distribution of moisture content in the cross-section is shown in Fig. 2. The oven-drying method was used to determine the moisture content.

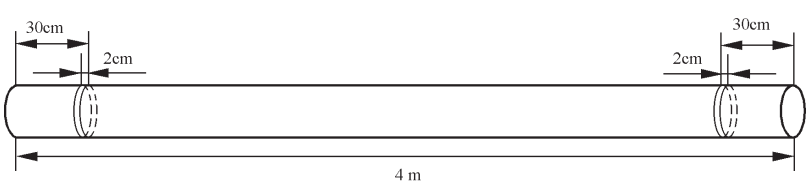

Fig. 1. Sampling method of disks for green MC measurement.
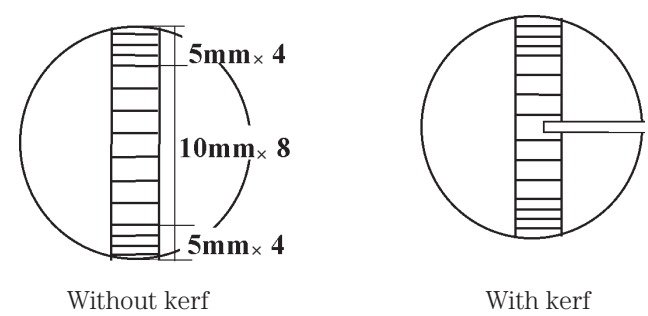

Fig. 2. Partition for measuring MC disks.

\section{Microwave drying}

Microwave drying was performed with log drying equipment (made by Asia Seisakusyo). Microwaves were irradiated intermittently (30 seconds irradiation, 12 seconds rest) until the round timbers reached the target temperature. The round timbers were then left in the ventilation booth without being heated further, and the weights and dimensions of the round timbers were 
measured automatically. At 30 minutes after the end of the microwave heating, the microwave irradiation and leaving were repeated according to the same schedule. This cycle was repeated until the target moisture content was reached.

The irradiation time per episode of microwave heating was calculated on the basis of the amount of energy needed to raise the temperature of the round timber up to the target temperature.

\section{Temperature measurement in microwave heating}

The round timbers were drilled using a $3 \mathrm{~mm}$ diameter drill at three positions along their length. These three holes were drilled into the outer layer ( $1 \mathrm{~cm}$ deep), the middle layer ( $3 \mathrm{~cm}$ deep), and the center layer $(6 \mathrm{~cm}$ deep), respectively (Fig. 3). Then, thermocouples (alumel-chromel) each covered with an aluminum stick of $3 \mathrm{~mm}$ in diameter were buried in the holes, and a silicon caulking agent was used to seal them in. The lines of the thermocouples were wrapped in aluminum foil so that thermocouples would not be affected by the microwaves. A personal computer with the NR-1500 data collection system (Keyence Corporation) was used for recording the temperature. These temperature data were sampled every one second during the process of heating with microwave irradiation and during the cooling process (about $10 \mathrm{~min}$ ) that followed the end of the irradiation.

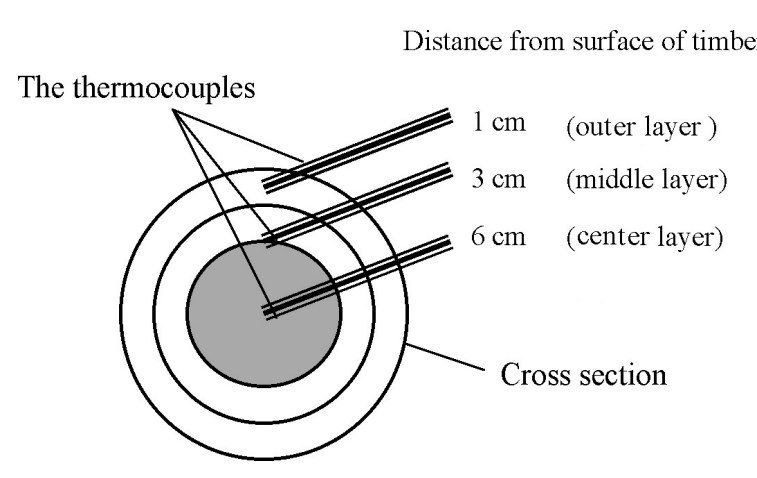

Fig. 3. Positions for measuring temperature of the round timber.

\section{Drying methods}

Three pieces of round timber with kerf and 3 without kerf were prepared for each of the 3 forms of drying, namely kiln drying, air drying, and microwave drying (Table 1). Three temperature models were used in the microwave drying method: $100^{\circ} \mathrm{C}, 120^{\circ} \mathrm{C}$ and $140{ }^{\circ} \mathrm{C}$. IF-type kiln drying was executed at DBT $80^{\circ} \mathrm{C}$ and WBT $70{ }^{\circ} \mathrm{C}$ for 48 hours. Air drying involved leaving the timbers indoors for two months. Both kiln drying and air drying were performed as controls for comparison with microwave drying (Table 2).

\section{Measurement}

The timber moisture content after drying was measured by the methods described above. The internal checks and surface checks were examined after drying.
Table 1. Number of timbers on each drying condition

\begin{tabular}{cccc}
\hline & Setting temperature & kerf & Number \\
\hline \multirow{2}{*}{$\begin{array}{c}\text { Microwave } \\
\text { heating drying }\end{array}$} & \multirow{2}{*}{$100^{\circ} \mathrm{C}$} & $\times$ & 3 \\
\cline { 2 - 3 } & \multirow{2}{*}{$120^{\circ} \mathrm{C}$} & $\times$ & 3 \\
\cline { 2 - 3 } & & $\bigcirc$ & 3 \\
\cline { 2 - 3 } & \multirow{2}{*}{$140^{\circ} \mathrm{C}$} & $\times$ & 3 \\
\hline \multirow{2}{*}{ Kiln drying } & $\mathrm{DBT} 80^{\circ} \mathrm{C}$ & $\bigcirc$ & 3 \\
\hline \multirow{2}{*}{ Air drying } & WBT $70^{\circ} \mathrm{C}$ & $\bigcirc$ & 3 \\
\hline
\end{tabular}

Table 2. Finishing moisture content of drying

\begin{tabular}{|c|c|c|c|c|c|c|}
\hline & \multirow{2}{*}{$\begin{array}{c}\text { Setting } \\
\text { temperature }\end{array}$} & \multirow{2}{*}{ kerf } & \multicolumn{4}{|c|}{ MC after drying (\%) } \\
\hline & & & Timber 1 & Timber 2 & Timber 3 & Average \\
\hline \multirow{6}{*}{$\begin{array}{c}\text { Microwave } \\
\text { heating } \\
\text { drying }\end{array}$} & \multirow{2}{*}{$100^{\circ} \mathrm{C}$} & $x$ & 27.5 & 31.9 & 29.2 & 29.5 \\
\hline & & $\bigcirc$ & 31.8 & 29.6 & 35.6 & 32.3 \\
\hline & \multirow{2}{*}{$120^{\circ} \mathrm{C}$} & $x$ & 31.6 & 27.2 & 37.4 & 32.1 \\
\hline & & $\bigcirc$ & 32.3 & 21.8 & 26.5 & 26.8 \\
\hline & \multirow{2}{*}{$140^{\circ} \mathrm{C}$} & $x$ & 29.9 & 20.8 & 28.2 & 26.3 \\
\hline & & $\bigcirc$ & 25.6 & 25.7 & 24.8 & 25.4 \\
\hline \multirow{2}{*}{ Kiln drying } & DBT $80^{\circ} \mathrm{C}$ & $\times$ & 22.3 & 53.0 & 28.4 & 34.5 \\
\hline & WBT $70^{\circ} \mathrm{C}$ & $\bigcirc$ & 42.9 & 27.7 & 40.3 & 36.9 \\
\hline \multirow{2}{*}{ Air drying } & \multirow{2}{*}{2 months } & $x$ & 20.3 & 20.9 & 22.0 & 21.1 \\
\hline & & $\bigcirc$ & 28.9 & 25.1 & 20.5 & 24.8 \\
\hline
\end{tabular}

Internal checks were estimated using the checking area visualized with image analysis. Surface checks were assessed using the total checking area appearing on the timber surface. During drying, the moisture content obtained from the assumptive oven-dry density was designated as the presumption moisture content $\left(M C_{1}\right)$, and that obtained from the moisture content by the oven-dry method after drying $\left(M C_{0}\right)$ was designated as the actual moisture content $\left(M C_{2}\right)$.

$$
\begin{aligned}
& M C_{1}(\%)=\frac{G-V \square D}{V \square D} \times 100 \\
& M C_{2}(\%)=\frac{G-\frac{G_{0}}{1+M C_{0} / 100}}{\frac{G_{0}}{1+M C_{0} / 100}} \times 100 \\
& V: \text { volume of a round timber } \\
& \left.D: \text { oven-dry density (assumed } 0.35 \mathrm{~g} / \mathrm{cm}^{3}\right) \\
& G: \text { timber weight during drying } \\
& G_{0}: \text { timber weight after drying process }
\end{aligned}
$$

\section{RESULTS AND DISCUSSION}

\section{Temperature distribution of the timber}

The temperature distribution of the timbers during microwave drying is one of the most important parameters for evaluating the efficiency of the drying method. So we first measured the internal temperature change in the timbers irradiated by microwaves during the $1^{\text {st }}, 3^{\text {rd }}$, $6^{\text {th }}$ and $15^{\text {th }}$ cycles. As shown in Fig. 4 , in the first cycle, 
the microwave required ten minutes or more of irradiating time to heat the timbers from room temperature to the target temperature. During the first stage of heating, the inner layer was heated as quickly as the outer layer. However, the surface temperature decreased markedly during the non-heating period of 12 seconds, and the surface temperature occasionally became lower than the inner temperature. The inner temperature of the wood showed a tendency to decrease as much as the outer layer immediately after the end of the heating. The round timber MC decreased with the progress of the microwave heating cycles. At the same time, the thermal capacity of the round timber also decreased. Moreover, the heating time required to raise the timbers up to the target temperature clearly became shorter in the latter cycles of microwave heating.

When the round timber was heated with microwaves, the surface temperature was raised more slowly than the temperature of the inner layer, especially in the latter stages. After the microwave heating, the surface temperature decreased more quickly than that of the inner layer. This finding may be attributed to the
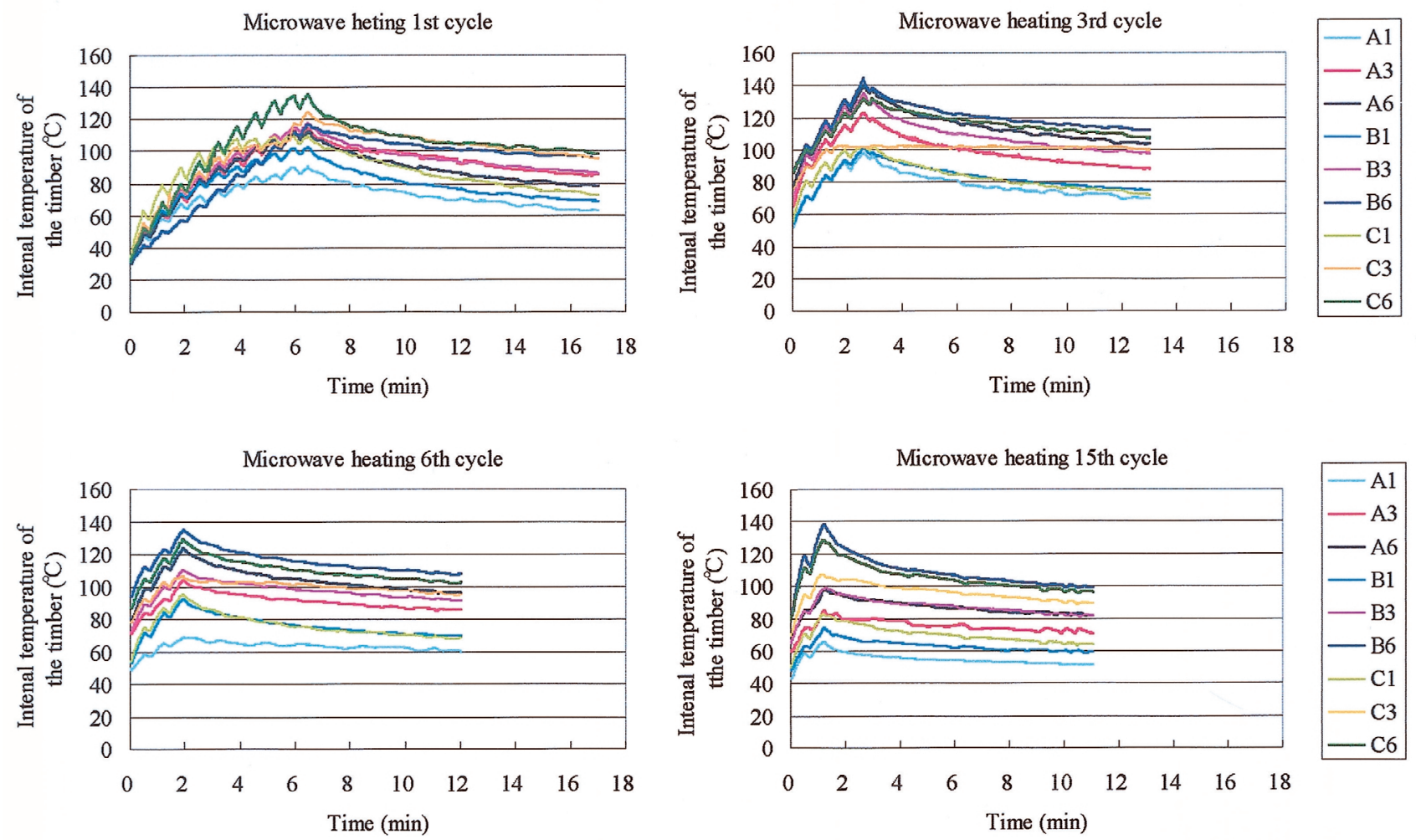

Fig. 4. Temperature change of timbers during microwave heating. Note: A1, B1, C1: The distance from the timber surface is $1 \mathrm{~cm}$. A3, B3, C3: The distance from the timber surface is $3 \mathrm{~cm}$. A6, B6, C6: The distance from the timber surface is $6 \mathrm{~cm}$. $\mathrm{A}, \mathrm{B}$ and $\mathrm{C}$ are three different points on the long direction of a timber.

Microwave heating drying

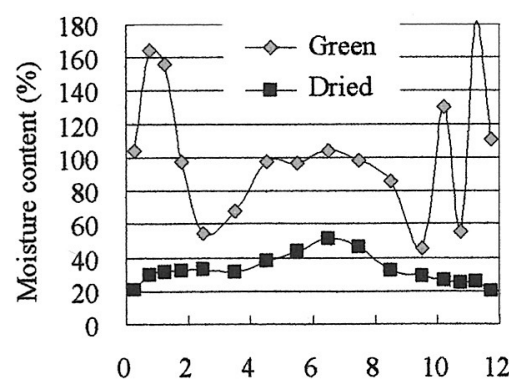

Distance from surface of timber $(\mathrm{cm})$
Kiln drying

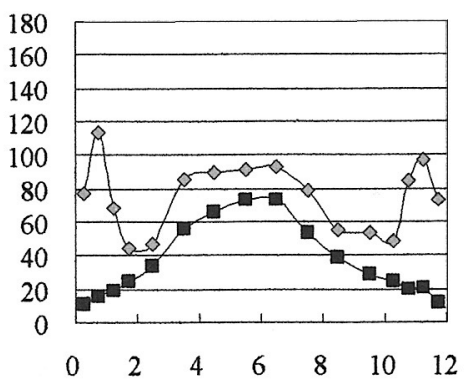

Distance from surface of timber $(\mathrm{cm})$
Air drying

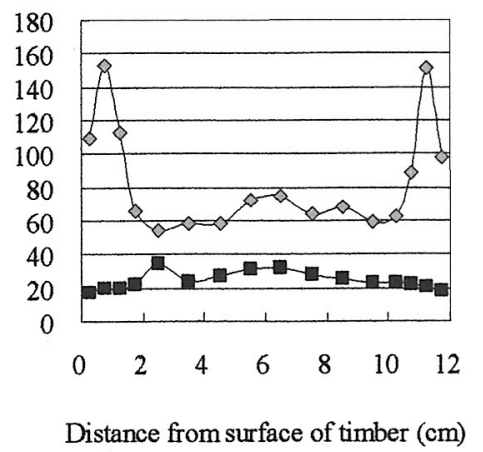

Fig. 5. Moisture content distribution in the direction of diameter for green and dried states. Note: Three timbers had not kerf. 
decreased surface energy absorptivity that results from the outer layer MC having dropped earlier than the inner MC. As a result, the inner temperature was higher than the surface temperature almost during the microwave drying. In addition, the difference between the inner and outer layer temperatures increased as the drying progressed. In the microwave drying method, the actual wood temperature often differed from the target temperature due to the varied density of the round timber (for example, the actual wood temperature was $120^{\circ} \mathrm{C}$, although the target temperature had been $100^{\circ} \mathrm{C}$ ).

Therefore, in this research, it was impossible to determine the effect of drying temperature on the drying properties of the timbers.

\section{MC distribution}

Fig. 5 shows the MC distribution before and after microwave drying. In microwave drying, the round
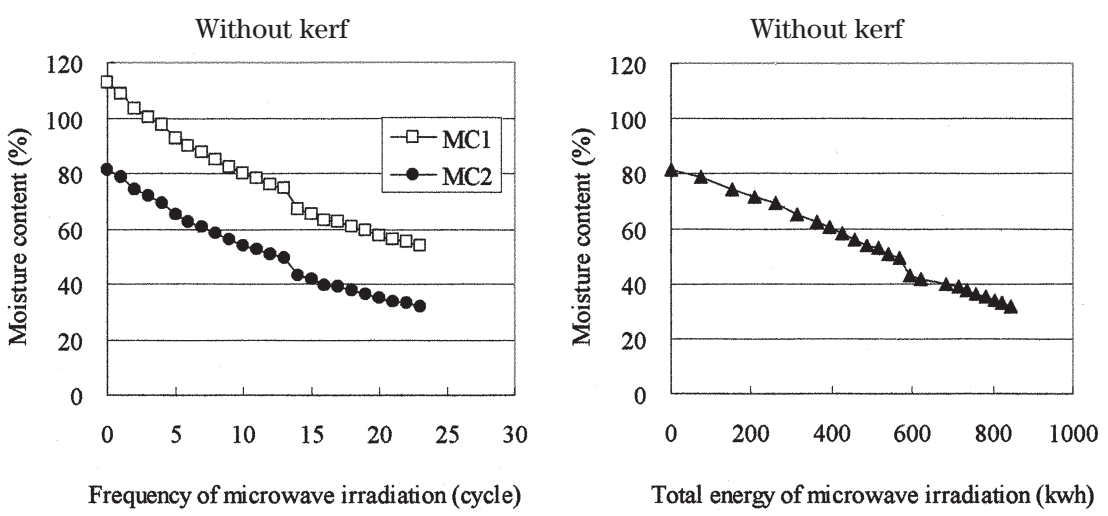

Fig. 6. Progressing of moisture content. Note: MC1-Estimated moisture content; MC2-Actual moisture content.

a) Without kerf

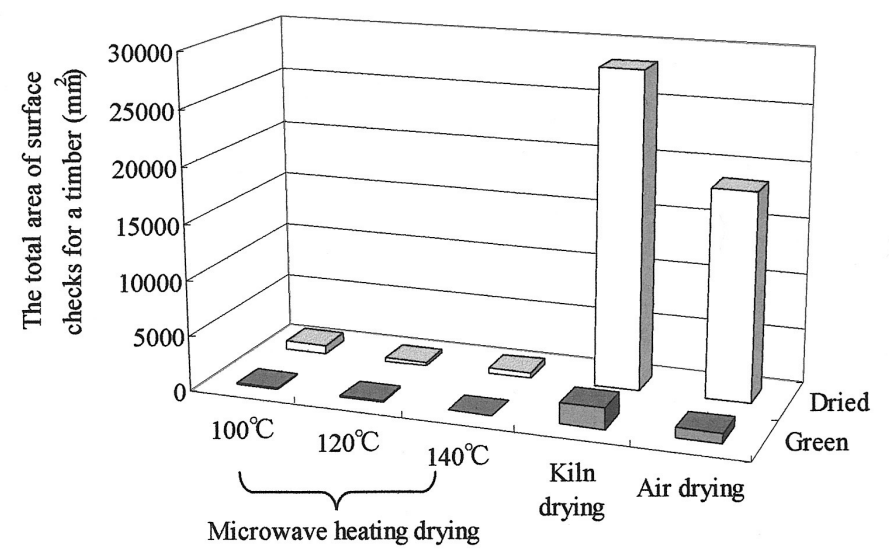

b) With kerf

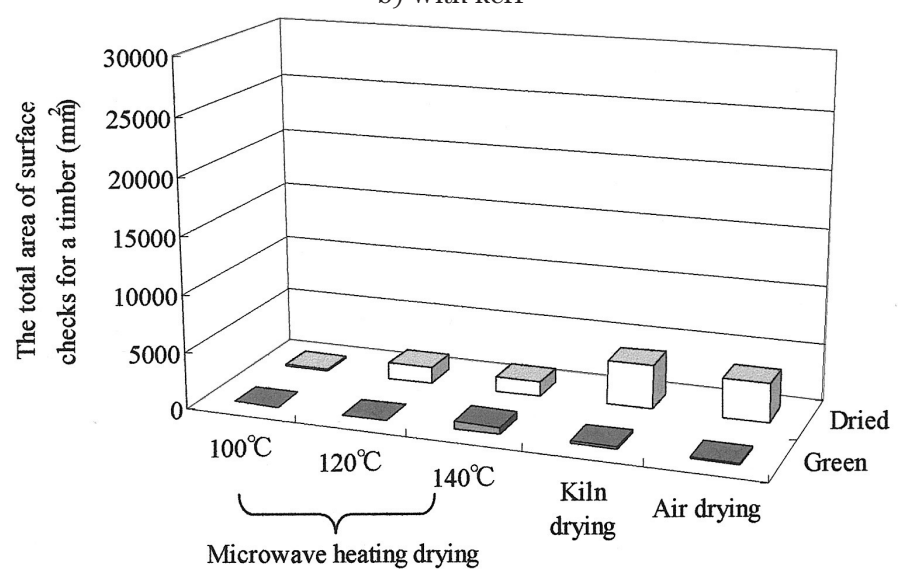

Fig. 7. The total area of surface checks of each drying condition. 
timbers were dried until the target MC of $30 \%$ was reached. In most of the tested periods, the temperature of the center layer was the highest measured in the cross-section. Therefore, the inner layer MC dropped significantly during the microwave drying, but almost did not drop at all during the kiln drying. The sap wood MC dropped as a result of both the microwave drying and kiln drying, but the inner layer MC was not reduced by kiln drying. There were few differences in moisture distribution between the bottom and top ends, even between the timbers with and timbers without a kerf. After two months of air drying, the average MC was lowered considerably more than in the other drying methods, and the MC distribution in the cross-section was comparatively uniform.

\section{Change of moisture content}

As the initial MC of the timber varied from about 50 to $130 \%$, the number of microwave heating cycles needed to dry them to a target of $30 \%$ moisture content was distributed from 10 to 40 cycles. Since a cycle took about 30 minutes, it was possible to dry the timbers to the desired moisture content within 24 hours. The change in $\mathrm{MC}$ resulting from the irradiation energy at different processing cycles is shown in Fig. 6. As the drying advanced, the MC decrease per cycle became smaller and smaller. However, there was a linearity relation between the irradiation energy and the MC. That is, it was found that the energy consumption corresponding to the decrease of the moisture content did not change even as the drying progressed.

\section{Surface checks}

The surface check area resulting from the drying is shown in Fig. 7. Based on these results, there were fewer surface checks on round timbers dried by microwave drying than on those dried with the kiln-drying and air-drying methods. The reason for this discrepancy seemed to be that the drying of the inner layer was promoted and the drying of the outer layer was suppressed by microwave heating in comparison with the kiln-drying method. Moreover, it was confirmed that the occurrence of the surface checks could be suppressed by the kerf in the kiln-drying and the air-drying methods.

\section{Internal checks}

Besides the surface checks, the occurrence of internal checks among the three different drying methods was also examined. There were no internal checks in the wood treated by the kiln-drying and air-drying methods. However, internal checks were observed in timbers dried by microwave heating at temperatures up to $100^{\circ} \mathrm{C}$.

\section{REFERENCES}

Fujimoto, N., H. Fujimoto, J. Kawabe and Y. Mataki 1994 Drying of boxed heart square timbers I. -Changes of surface stress and cross-sectional shrinkage of dehumidifier kiln-dried timbers of sugi. Mokuzai Gakaishi, 40(7): 758-765

Fujimoto, N., Y. Morita, T. Oouchi, H. C. Lin, K. Oohashi and K. Kondo 2005 Drying of sugi Logs with microwave heating. $J$. soc. Mat. Sci., Japan, 54(4): 371-376 